\title{
Comparison of stress level and coping strategy between therapeutic phases in newly diagnosed tuberculosis
}

\author{
Ni Putu Wulan Purnama Sari, Ayu Kurnia Endar Sari \\ Departement of Palliative Nursing, Faculty of Nursing, Widya Mandala Catholic University Surabaya, Indonesia
}

\begin{tabular}{l} 
Article Info \\
\hline Article history: \\
Received Jan 31, 2020 \\
Revised Apr 7, 2020 \\
Accepted Apr 26, 2020 \\
\hline
\end{tabular}

\section{Keyword:}

Coping

Newly diagnosed

Stress

Therapeutic phase

Tuberculosis

\begin{abstract}
In newly diagnosed Tuberculosis (TB), the diagnosis and therapy duration may cause psychological stress requiring effective coping strategy. This study aimed to compare and analyze the differences of stress level and coping strategy between intensive and advanced phases in newly diagnosed TB. This cross-sectional study involved 16 respondents in intensive phase and 29 respondents in advanced phase $(n=45)$, in the working area of Pacar Keling Public Health Center of Surabaya. Perceived Stress Scale (PSS) and coping strategy questionnaire were used for collecting data. Data were collected in May 2018. Independent sample t test was used in data analysis $(\alpha<0.05)$. Results showed that mostly moderate stress level and adaptive coping strategy were found in both phases. Overall, stress and coping were not significantly different between phases in newly diagnosed TB ( $\mathrm{p}=0.259$ and $\mathrm{p}=0.079$ respectively), but the feeling of angry, losing control, nervous \& depressed, whether things happened as wishes, talking problems to professionals, and trying new dangerous thing were differ significantly between phases $(\mathrm{p}=0.046, \mathrm{p}=0.024, \mathrm{p}=0.044, \mathrm{p}=0.016, \mathrm{p}=0.014$, and $\mathrm{p}=0.005$ respectively). Although stress level and coping strategy were not significantly different between therapeutic phases in newly diagnosed TB, but more attention needs to be given towards patients' emotion, such as the feeling of angry, losing control, nervous and depressed, and patients' wishes, especially in intensive phase.
\end{abstract}

This is an open access article under the CC BY-SA license.

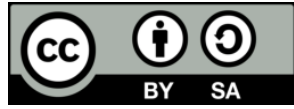

\section{Corresponding Author:}

Ni Putu Wulan Purnama Sari,

Faculty of Nursing, Department of Palliative Nursing,

Widya Mandala Catholic University Surabaya,

Jl. Raya Kalisari Selatan 1, Pakuwon City, Surabaya, Indonesia.

Email: wulanpurnama@ukwms.ac.id

\section{INTRODUCTION}

Tuberculosis (TB) is an infectious disease caused by bacteria of Mycobacterium tuberculosis (M.tb) which transmitted through inhaled droplets [1]. Clinical manifestations of TB consist of fever, decreased appetite, coughing up phlegm for 3 weeks or more; cough can be followed by phlegm mixed with blood, malaise, and shortness of breath [2]. Globally, TB holds the $9^{\text {th }}$ rank of the leading cause of death by single infectious agent in 2017. Indonesia ranks second in the highest number of TB cases in the world after India [3]. It was estimated that the new cases of TB in Indonesia was 647 cases per 100,000 population. In 2016, the top five provinces in Indonesia with the highest number of new TB cases were West Java (23,774 cases), East Java (21,606 cases), Central Java (14,139 cases), North Sumatra (11,771 cases), and Special Capital Region of Jakarta (9,516 cases). Based on the coverage of TB case findings, the top five provinces in Indonesia were West Java (52,328 cases), East Java (45,239 cases), Central Java (28,842 cases), Special Capital Region of Jakarta (24,775), and North Sumatra (17,798 cases) [4]. 
A study from 2008 to 2011 towards 404 clinical specimen from sputum smears TB patients, age $\geq 15$ years, which were collected from 16 TB referral primary health centers (PHC) in 16 provincial capitals in Indonesia showed that $23 \%$ were from the Beijing family, and it was confirmed that the Beijing family of M.tb in Indonesia exhibited greater resistance to first line anti-TB drugs than did other families [5]. This finding is also consistent with a previous cohort study towards 818 TB cases which proved that the Beijing genotype (33.4\%) was an independent risk factor for TB treatment failure in Indonesia, therefore this genotype has a higher capacity to withstand TB treatment even in the absence of drug resistance [6]. Generally, the therapy success rate in Indonesia is 75.4\%, which is lower than the World Health Organization (WHO) target $(85 \%)$ and Indonesian Ministry of Health (MoH) target (88\%) in 2014 [7]. Surabaya is the capital of East Java province. In 2015, the top five cities with most treated TB patients in East Java province were Surabaya (4,754 cases), Jember (3,128 cases), Sidoarjo (2,292 cases), Malang (1,932 cases), and Pasuruan (1,809 cases) [8].

TB can be cured by direct treatment with anti-TB drugs (OAT) for a period of 6 months at least. This 6 months period is divided into 2 phases: the first 2 months is considered as intensive phase in which most patients experience sputum conversion (from + become -), and the rest 4 months is considered as advanced phase aiming at killing persistent M.TB to avoid recurrence [9]. Guidelines of TB therapeutic management in Indonesia from Ministry of Health $(\mathrm{MOH})$ stated that for newly diagnosed TB patients, first category/line of OAT was given to clinically-diagnosed pulmonary TB patients with or without bacteriological contamination. In the intensive phase, TB patients required to eat drugs regularly everyday in which family supervision is highly needed to avoid drug resistance [10]. If this phase pasts successfully then in a period of 2 weeks after initial treatment the TB patients will not become contagious to others [11]. Therefore, intensive phase requires more attention, adherence, and commitment. WHO (2004) has published the guidelines of TB treatment to be used as an international standard of TB treatment. There are 4 types of drugs need to be consumed everyday regularly in the intensive phase, such as: Isoniazid (Z), Rifampicin (R), Pyrazinamide (H), and Ethambutol (E). In comparison, there are 2 types of drugs need to be consumed in three-times-a-week basis in advanced phase, such as: Isoniazid ( $\mathrm{Z}$ ) and Rifampicin (R) only. Fewer drugs and lower frequency are needed in advanced phase [12].

TB control success is based on the patient's compliance to the treatment [13]. Long duration of treatment results in non-adherence in TB patients, especially the one with forgetfulness. Non-adherence to anti-TB treatment is one of the crucial challenges in improving TB cure rates and reducing further healthcare costs [14]. Treatment non-adherence results in treatment failure, prolonged transmission of disease and emergence of drug resistance in TB [15].

Limited treatment options, long duration of treatment, and associated toxicity adversely impact the mental well-being, such as stress, in TB patients [16]. TB diagnosis and therapeutic complexity may also cause psychological stress in TB patients. Prior study results showed that stress level is strongly correlated with coping strategy in newly diagnosed TB patients $(\rho=0.532, p=0.000)$ [17]. There is a high possibility that the newly diagnosed TB patients experience elevated stress level due to therapeutic complexity especially in intensive phase, and it slowly decrease in advanced phase due to fewer drugs consumed and lower frequency of drug consumption. This study aimed to compare and analyze the differences of stress level and coping strategy between intensive and advanced phases in newly diagnosed TB patients.

\section{RESEARCH METHOD}

This cross-sectional study involved 45 newly diagnosed TB patients, 16 in intensive phase and 29 in advanced phase, from Public Health Center (PHC) of Pacar Keling, Surabaya, Indonesia. Inclusion criteria were being an adult (> 18 years old) so that they could take the responsibility as study respondent independently, TB diagnosis has been confirmed by the PHC, regularly consumed medication based on therapeutic regiments from PHC doctor, and had a medication supervisor at home to assure treatment adherence. Exclusion criteria were rejection on filling out the consent form, hospitalized in the time of data collection, and unclear address (because of door-to-door data collection method). Simple random sampling was applied and sample size of 45 was obtained.

Instrument of Perceived Stress Scale (PSS) by Cohen (1983) was used to measure the stress level [18]. It consisted of 10 items in five responses Likert scale format (0-4). The items were (1) feeling of angry, (2) losing control, (3) nervous and depressed, (4) self-efficacy towards personal problem solving ability, (5) whether things happened as wishes, (6) inability to finish assigned work, (7) manage sensitive feeling, (8) ability to solve personal problems, (9) angry towards unsolved problems, and (10) feeling of accumulated difficulties resulted in inability to solve them. Stress level was categorized into three based on the total score: mild (0-13), moderate (14-27), and severe stress (28-40). Actually there are some conditions which potentially influence individual stress level, such as pregnancy, physical or psychological disease 
(HIV, adrenal or mental disorders, depression, etc.), but this instrument may be applied generally to any person in any condition. Cohen (1983) did not specified the target population of this PSS. The wide exclusion criteria in this study context may become the study limitation.

Researchers developed a questionnaire to measure coping strategy in TB patients based on the domains proposed by Stuart \& Sundeen (2007) [19] in combination with Carver (1989) [20]. It consisted of 12 items in four responses Likert scale format (1-4). The items were (1) self-blaming due to inability to maintain health status, (2) ability to take advantages from personal problems, (3) wishful thinking in facing problems due to the disease, (4) talking problems to professionals, (5) trying new dangerous thing at home, (6) escaping from others due to the disease, (7) enjoying life under difficult circumstances, (8) keeping sickness as a secret from others, (9) praying and stay close to God, and (10) feeling desperate towards treatment, (11) eliminating stress by sleeping and doing nothing, (12) feeling angry and blaming others due to the problems. Coping strategy was categorized into two: adaptive (31-48) and maladaptive coping strategy (12-30).

A preliminary study towards 30 respondents which conducted in the working area of Kedungdoro PHC, Surabaya, in April 2018 showed that PSS and the coping strategy questionnaire were valid and reliable instruments (PSS: $r=0.410-0.772$, Chronbach Alpha=0.820; coping strategy questionnaire: $r=0.081-0.839$, Chronbach Alpha = 0.897) [21]. Data were collected in May 2018. Prior to data collection process, this study protocol has been reviewed by Faculty of Nursing, Widya Mandala Catholic University Surabaya, and informed consent preceded participation. Descriptive statistic and independent sample t test were used in data analysis $(\alpha<0.05)$.

\section{RESULTS AND ANALYSIS}

Stress is a physical and psychological response towards physical, social, and psychological stressors resulted in tension and daily life stability disturbance [22]. Stress has an impact in physically ill individual due to the weakness and slow response of the immune system by the time it happens [23]. There are various factors affecting stress response internally and externally, such as: age, gender, personality, cognitive function, family situation, physical and social environment, disease and treatment duration [24]. In stress condition, human body will give a response physiologically by mechanism: immune system is stimulated by various stressors affecting PVN (paraventricular nucleus), then the neurons will synthesize corticotropin releasing hormone (CRH) and arginine vasopressin (AVP) stimulating the adrenocorticotropin hormone (ACTH) which releases the glucocorticoids and cortisol hormone for the process of coping with stressors [25]. Stress manifestation could be seen in physical, emotional, cognitive, and behavioral symptoms [23].

Coping is an individual way to solve problems, adjusting to changes, and responding towards threatening situation [26]. Coping mechanism is the way a person adjusts to a stressor psychologically, physically, and behaviorally; this is someone's ability to deal with problems and stress consciously [27]. Effective coping to do is a coping to help all people to tolerate and accept stressful situations [28]. Stuart and Sundeen (2007) categorized coping into two types: adaptive and maladaptive coping strategy [19]. Adaptive coping consisted of active coping, social support seeking behavior, positive reinterpretation, self-control, planning, situational acceptance, religious coping, and humor. In the other hand, maladaptive coping consisted of refusal, chemical substance usage, emotional social support seeking behavior, behavioral loose, emotional-focused behavior, mental loose, and emphasis to compete. There are various factors affecting coping, such as: age, gender, educational level, marital status, and social support [28, 29]. Table 1 explains the demography characteristic of study respondents in details. Most respondents were married male pre-elderly with sufficient educational background which still working as a private employee.

In this study, most respondents were aged 56-65 years old $(24.44 \%)$ that is considered as pre-elderly to elderly population. Elderly without TB experience somatic, cultural, and economical stress due to physical, psychological, and social changes; while the presence of TB worsen the stress condition because of its clinical manifestation and treatment. Age is not only influence the stress level, but also the coping strategy. The stressor experienced by each stage of life represented by age differences was varied due to variation in demands, life challenges, experiences, preferences, personal values and beliefs, etc. Siswanto (2007) stated that age can be related with individual stress tolerance and the most disturbing type of stressor [29].

In this study, most respondents were males $(57.78 \%)$. Males and females have different tendency in responding stressors. Males tend to implement fight-or-flight technique while females tend to implement tend-and-befriend technique [30]. Males seemed to prefer confrontation, while females seemed to prefer withdrawal or escape. Differences in stress response between males and females are closely related to hipofisispituitary-adrenal (HPA) axis activities by regulating cortisol hormone and sympathetic nervous system associated with heart rate and blood pressure. The HPA axis and autonomic nervous responses are found higher in adult males compared to adult females resulted in performance differences in responding the stressors [31]. 
Table 1. Demography characteristic

\begin{tabular}{lcc}
\hline \multicolumn{1}{c}{ Characteristic } & Frequency & Percentage \\
\hline 1. Age (years old) & 9 & \\
a. $17-25$ & 7 & 15.00 \\
b. $26-35$ & 8 & 17.78 \\
c. $36-45$ & 9 & 20.00 \\
d. $46-55$ & 11 & 24.44 \\
e. 56-65 & 1 & 2.22 \\
f. > 65 & & \\
2. Gender & 26 & 57.78 \\
a. Male & 19 & 42.22 \\
b. Female & & \\
3. Marital status & 6 & 13.33 \\
a. Single & 33 & 73.33 \\
b. Married & 6 & 13.33 \\
c. Widowed & & \\
4. Education level & 8 & 17.78 \\
a. Primary school & 5 & 11.11 \\
b. Secondary school & 29 & 64.44 \\
c. High school & 3 & 6.67 \\
d. Diploma/bachelor degree & & \\
5. Occupation & 5 & 11.11 \\
a. None & 9 & 20.00 \\
b. Housewife & 4 & 8.89 \\
c. Entrepreneur & 27 & 60 \\
d. Private employee & & \\
\hline & &
\end{tabular}

Most respondents in this study were high school graduated (64.44\%). Educational background affects individual stressor control, the higher the educational background then the better the stress tolerance and stressor control [29]. High educational level makes individual has broader perspective about everything in life, higher knowledge possessed makes someone accepts new ideas or life ways easily and tend to implement more adaptive coping strategy. Low educational level resulted in intellectual limitation so that behavior or stress response still influenced by environmental situation and there will be a tendency of maladaptive coping strategy implemented [32]. Marital status implicates family support, medication supervisor, and housing social environment in this study context. Most respondents in this study are married (73.33\%), and spouse became the medication supervisor at home as shown in Table 2 (57.78\%). Marital status is reported to be associated with adherence to anti-TB treatment [33]. Non-adherence to TB treatment was high if the patients had forgetfulness [14]. Therefore the role of medication supervisor is very important because she reminds and motivates TB patients to follow the regiments correctly and persistently. Family can provide informational, instrumental, financial, and emotional support towards each other [29].

Primary data in this study context consisted of the time of first TB diagnosis, treatment duration, anti-TB drug consumption, and the medication supervisor at home. Table 2 explains the primary data of study respondents in details. Most respondents were diagnosed with TB since November 2017-January 2018 (44.44\%) and in May 2018 they were in advanced phase (64.44\%) with mostly 5-6 months treatment duration $(48.89 \%)$. The OAT consumed by most respondents was RH (Rifampicin+Pyrazinamide) [55.56\%].

Table 2. Primary data

\begin{tabular}{|c|c|c|}
\hline Characteristic & Frequency & Percentage \\
\hline \multicolumn{3}{|l|}{ 1. Firstly diagnosed } \\
\hline a. February - April 2018 & 16 & 35.56 \\
\hline b. November 2017 - January 2018 & 20 & 44.44 \\
\hline c. August - October 2017 & 7 & 15.56 \\
\hline d. May - July 2017 & 2 & 4.44 \\
\hline \multicolumn{3}{|l|}{ 2. Treatment duration (months) } \\
\hline a. 1-2 (intensive phase) & 16 & 35.56 \\
\hline b. 3-4 (advanced phase) & 7 & 15.56 \\
\hline c. 5-6 (advanced phase) & 22 & 48.89 \\
\hline \multicolumn{3}{|l|}{ 3. Drugs consumed } \\
\hline a. RHZE & 13 & 28.89 \\
\hline b. RH & 25 & 55.56 \\
\hline c. $\mathrm{RH}+$ Ethambutol & 4 & 8.89 \\
\hline $\begin{array}{l}\text { d. RHZE + Streptomycin injection } \\
\text { 4. Medication supervisor }\end{array}$ & 3 & 6.67 \\
\hline a. Spouse & 26 & 57.78 \\
\hline b. Child & 6 & 13.33 \\
\hline c. Parent & 9 & 20.00 \\
\hline d. Sibling & 4 & 8.89 \\
\hline
\end{tabular}

Int. J. Public Health Sci, Vol. 9, No. 2, June 2020: 145 - 152 
TB can be cured by long treatment duration, at least 6 months [9]. Mumpuni (2010) stated that long treatment duration resulted in psychological stress with frustration being one of the symptoms [23]. Table 3 explains the comparison of stress level and coping strategy between intensive and advanced phase in newly diagnosed TB patients. These results indicated that whether most respondents experienced moderate level of stress but they could manage it well by implementing adaptive coping strategy. This potentially resulted in better therapeutic outcome, such as sputum conversion in the end of intensive phase and avoidance of TB recurrence in the end of advanced phase.

Table 3. Measured variables

\begin{tabular}{ccccc}
\hline \multirow{2}{*}{ Characteristic } & \multicolumn{2}{c}{ Intensive phase $(\mathrm{n}=16)$} & \multicolumn{2}{c}{ Advanced phase $(\mathrm{n}=29)$} \\
& Frequency & Percentage & Frequency & Percentage \\
\hline 1. Stress level & & & & \\
$\quad$ a. Low & 4 & 25.00 & 5 & 17.24 \\
b. Moderate & 10 & 62.50 & 22 & 75.86 \\
$\quad$ c. High & 2 & 12.50 & 2 & 6.90 \\
2. Coping strategy & & & & \\
a. Adaptive & 11 & 68.75 & 27 & 93.10 \\
b. Maladaptive & 5 & 31.25 & 2 & 6.90 \\
\hline
\end{tabular}

The majority of respondents experienced moderate stress level in intensive and advanced phases (62.5\% and $75.86 \%$ respectively), and there was no significant difference of stress level between both phases in newly diagnosed TB patients $(\mathrm{p}=0.259)$. This result was supported by a study of Chilyatiz and Subai'ah (2016) which found that most of newly diagnosed TB patients who got $1^{\text {st }}$ line of OAT experienced moderate stress level (63\%) [34]. Iqra, et al. (2016) also found that most of newly diagnosed TB patients who got $1^{\text {st }}$ line of OAT experienced moderate stress level (86.2\%) [35]. Both studies did not differentiate the respondents into intensive and advanced phases like in this study context, but their results were similar in general.

Overall, stress level between therapeutic phases was not significantly different in newly diagnosed TB patients. But, deeper analysis of independent sample t test towards each item of PSS showed that the feeling of angry, losing control, nervous \& depressed, and whether things happened as wishes were differs significantly between phases $(\mathrm{p}=0.046, \mathrm{p}=0.024, \mathrm{p}=0.044$, and $\mathrm{p}=0.016$ respectively). Results showed that various emotions existed during TB treatment. There is no specific study in TB patients about their emotion during TB treatment. This is important to predict stress level determinant, especially in newly diagnosed TB patients. In the other hand, few studies about depression and other common mental disorder has been studied in TB context, especially in multi-drug-resistant TB patients. Mental disorders, such as depression, might contribute to the burden of TB as a chronic disease. There appears to be a positive and independent association between common mental disorders and TB [36]. Depressive disorders have been negatively associated with compliance of therapeutic schemes for chronic diseases generally. Depression could be a hazard factor for negative outcomes in TB patients receiving treatment, including abandon or death [13].

Study about correlation between angriness and stress in TB is not found online yet. But Mycobacterium tuberculosis sigF is proved to be an alternative sigma factor implicated in stress response [37]. A study in another context, recurrent aphthous stomatitis (RAS), showed that among subjects with high angriness or anxiety, RAS subjects showed higher stress level. Therefore anger/anxiety level mediates the relationship between stress level and RAS [38]. In this study, we found that angriness differ significantly between intensive and advanced phases in newly diagnosed TB. This potentially happened due to the significant difference in therapy duration. As shown in Table 2, intensive phase only occurs for the first two months, while the advanced phase occurs in month 3-6. Therefore, respondents in advanced phase experienced longer therapy duration so that the angriness response also higher, and this reflects higher stress level.

Feeling nervous and depressed are two negative emotional constructs found in TB patients. The study about nervous and TB is not found online yet. Oppositely, there are various studies about depression in TB patients. The prevalence of depression is high in TB patients currently on DOTS or TB therapy [39]. Depression has adverse effect on TB treatment and drug compliance. Depression is also prevalent among hospitalized TB patients, especially young or elderly male, which caused by altered social relationship or TB stigma in female [40]. A study towards 84 subjects who were initially diagnosed with TB showed that TB stigma together with body mass index were accounted for $34 \%$ of the variation in depression [41]. In this study, depression was significantly different between therapeutic phases. This potentially happened due to altered social relationship or TB stigma which is more possible to happen 
in the advanced phase compared to intensive phase. Another study towards $648 \mathrm{~TB}$ patients under treatment showed that if depression was untreated then the result will be worse treatment outcomes, poorer quality of life, and greater disability [42]. Therefore, health care professional needs to pay more attention to depression in TB patients under treatment, especially in those under advanced phase.

Patients' wishes related to TB treatment are mostly studied in qualitative paradigm. A qualitative study in Japan towards 11 public health nurses (PHNs) revealed that when patients became discouraged, PHNs listened to patients' wishes regarding drug adherence and hospitalization, and they tailored treatment accordingly, recognizing and respecting patient independence, and involving patients' natural support system to assist in treatment adherence [43]. In this study, patients' wishes were significantly different between therapeutic phases. But, we did not conduct any interview towards study respondents, so that this aspect remains unclear. There is a possibility that patients' wishes become more realistic in those under advanced phase because they were experienced with DOTS treatment and better understand the treatment goals.

Most of respondents implemented adaptive coping strategy in both therapeutic phases $(68.75 \%$ and $93.10 \%$ for intensive and advanced phases respectively), and there was no significant difference of coping strategy between phases in newly diagnosed TB patients $(\mathrm{p}=0.079)$. This result was supported by a study of Gilang \& Zaenal (2016) which found that under-treatment TB patients were mostly implemented adaptive coping strategy $(86.2 \%)$ due to family support [44]. But, this study also did not differentiate the respondents into intensive and advanced phases, and family support may be seen as medication supervisor in this study context as shown in Table 2 in which spouse being the most involved person in DOTS monitoring at home.

Overall, coping strategy between therapeutic phases was not significantly different in newly diagnosed TB patients. Deeper analysis of independent sample t test towards each item of coping strategy questionnaire showed that talking problems to professionals and trying new dangerous thing were also differs significantly between phases $(\mathrm{p}=0.014$ and $\mathrm{p}=0.005$ respectively). Talking problems to health professionals could be done by face to face meeting or using means of telecommunication devices, such as mobile phone, email, social media, etc. For face to face meeting, there are some barriers becoming challenges, such as the distance to health institution, financial capacity, means of transportation, family support to become a company, etc. Feeling distance to health institution is long and waiting time $>1$ hour during service were found to be determinants of non-adherence to TB treatment [45]. Related to depression, the new dangerous thing meant in this context includes suicide. Depression could be a hazard factor for death in TB patients receiving treatment [13]. Therefore psychological counseling and educational interventions could be beneficial for improving treatment adherence in TB patients [15].

\section{CONCLUSION}

Moderate stress level and adaptive coping strategy was mostly found in newly diagnosed TB patients, both in intensive and advanced phase of TB treatment. Stress level and coping strategy between both therapeutic phases were not significantly different. More attention needs to be given towards the feeling of angry, losing control, nervous \& depressed, and patients' wishes in intensive phase result in stress during treatment. Those in intensive phase need more assistance and consultation from professionals due to less communication about health problems with professional and the tendency to try new dangerous thing during treatment. Health care proffessional are reccommended to provide sufficient time for doing individual consultation during intensive phase of treatment so that the psychological and emotional needs of TB patients may be addressed.

\section{ACKNOWLEDGEMENTS}

This study was supported for publication by Faculty of Nursing, Widya Mandala Catholic University Surabaya.

\section{REFERENCES}

[1] Z. Amin, A. Bahar, "Pulmonary Tuberculosis (in Bahasa Indonesia)," Jakarta: Center for Publishing, Department of Internal Medicine, Faculty of Medicine, Universitas Indonesia, 2014.

[2] W. S. Aru, "Textbook of Internal Medicine, Volume II, $5^{\text {th }}$ Edition (in Bahasa Indonesia)," Jakarta: Interna Publishing, 2009.

[3] World Health Organization (WHO), “Global Tuberculosis Report 2017," 2017. [Online]. Available: http://www.who.int/tb/publications/global_report/gtbr2017_main_text.pdf?ua=1

[4] Ministry of Health (MOH), Republic of Indonesia (RI), "Indonesian Health Profile in 2016 (in Bahasa Indonesia),” 2017. [Online]. Available: http://www.depkes.go.id/resources/download/pusdatin/profil-kesehatanndonesia/Profil-Kesehatan-Indonesia-2016.pdf

Int. J. Public Health Sci, Vol. 9, No. 2, June 2020: 145 - 152 
[5] V. Lisdawati, N. Puspandari, et.al., "Molecular Epidemiology Study of Mycobacterium tuberculosis and Its Susceptibility to Anti-tuberculosis Drugs in Indonesia," BMC Infectious Diseases, vol. 15, no. 366, 2015.

[6] I. Parwati, B. Alisjahbana, et.al., "Mycobacterium tuberculosis Beijing Genotype is An Independent Risk Factor for Tuberculosis Treatment Failure in Indonesia," The Journal of Infectious Disease, vol. 201, no. 4, pp. 553-557, 2010.

[7] Ministry of Health, Republic of Indonesia, "Indonesian Health profile 2014 (in Bahasa Indonesia)," 2015. [Online]. Available: http://www.depkes.go.id/resources/download/pusdatin/profil-kesehatan-indonesia/profilkesehatan-indonesia-2014.pdf.

[8] Office of Communication and Informatics, East Java Province, "A total of 207,667 TB Patients in East Java were Successfully Healed (in Bahasa Indonesia),” 2016. [Online]. Available: http://kominfo.jatimprov.go.id/read/umum/sebanyak-207-667-pasien-tb-di-jatim-berhasil-disembuhkan

[9] M. N. Mertaniasih, B. E. Koendhori, D. Kusumaningrum, "Textbook of Microbiology Diagnostic Tuberculosis (in Bahasa Indonesia), " Surabaya: Center for Publishing, Universitas Airlangga, 2013.

[10] Ministry of Health (MOH), Republic of Indonesia (RI), "National Guidelines of TB Management (in Bahasa Indonesia), " Jakarta: Department of Public Health, 2014.

[11] K. Schwartzman, D. Menzies, "How Long are TB Patients Infectious?," CMAJ, vol. 163, no. 2, pp. 157-158, 2000.

[12] World Health Organization, "Treatment of Tuberculosis: Guidelines for National Programmes ( $3{ }^{\text {rd }}$ Edition), “ 2004. [Online]. Available: https://www.who.int/tb/publications/tb_2003_313_chap4_rev.pdf

[13] C. Ugarte-Gil, P. Ruiz, C. Zamudio, L. Canaza, L. Otero, et al., "Association of Major Depressive Episode with Negative Outcomes of Tuberculosis Treatment," PLoS One, vol. 8, no. 7, pp. e69514, 2013.

[14] A. A. Adane, K. A. Alene, D. N. Koye, B. M. Zeleke, "Non-adherence to Anti-Tuberculosis Treatment and Determinant Factors among Patients with Tuberculosis in Northwest Ethiopia," PLoS ONE, vol. 8, no. 11, pp. e78791, 2013.

[15] H. H. Tola, et.al., "Psychological and Educational Intervention to Improve Tuberculosis Treatment Adherence in Ethiopia Based on Health Belief Model: A Cluster Randomized Control Trial," PLoS ONE, vol. 11, no. 5, pp. e0155147, 2016.

[16] B. E. Thomas, et.al., "Psycho-socio-economic Issues Challenging Multidrug Resistant Tuberculosis Patients: A Systematic Review," PLOS ONE, vol. 11, no.1, pp. e0147397, 2016.

[17] A. Y. K. Sari, Y. D. Werdani, N. P. W. P. Sari, "Correlation between Stress Level and Coping Mechanism in Under Treatment Pulmonary TB Patients (in Bahasa Indonesia), " Surabaya: Faculty of Nursing, Widya Mandala Catholic University Surabaya, 2018.

[18] S. Cohen, T. Kamarck, R. Mermelstein, "A Global Measure of Perceived Stress," Journal of Health and Social Behavior, vol. 24, pp. 385-396, 1983.

[19] G. W. Stuart, S. J. Sundeen, "Handbook of Mental Health Nursing, $5^{\text {th }}$ Edition (in Bahasa Indonesia)," Jakarta: EGC, 2007.

[20] C. S. Carver, M. F. Scheier, J. K. Weintraub, "Assessing Coping Strategies: A Theoretically Based Approach," Journal of Personality and Social Psychology, vol.56, no.2, pp. 267-283, 1989.

[21] A. K. E. Sari, "Bachelor Thesis: Correlation between Stress Level and Coping Mechanism in Under Treatment Lung Tuberculosis Patients (in Bahasa Indonesia)," Surabaya: Faculty of Nursing, Widya Mandala Catholic University Surabaya.

[22] Priyoto, “Theory of Attitude and Behavior in Health (in Bahasa Indonesia), ” Yogyakarta: Nuha Medika, 2014.

[23] Y. Mumpuni, "Excellent Trick in Managing Stress (in Bahasa Indonesia), " Yogyakarta: CV. Andi Offset, 2010.

[24] A. Arora, "5 Steps to Avoid and Manage Stress (in Bahasa Indonesia)," Jakarta: PT. Bhuana Ilmu Populer, 2008.

[25] B. Gunawan, Sumadiono, "Stress and Body Immune System: A Psychoneuro-Immunological Approach (in Bahasa Indonesia)," Cermin Dunia Kedokteran, vol. 154, pp. 13-14, 2007.

[26] B. A. Keliat, “Community and Mental Health Nursing (in Bahasa Indonesia), ” Jakarta: EGC, 2011.

[27] L. M. Gorman, R. F. Anwar, “Neeb's Fundamentals of Mental Health Nursing,” USA: Davis Company, 2014.

[28] Rasmun, "Stress, Coping, and Adaptation: Theory and Nursing Problem Tree (in Bahasa Indonesia), " Jakarta: CV Sagung Seto, 2009.

[29] Siswanto, "Mental Health: Concept of Scope and Development (in Bahasa Indonesia)," Yogyakarta: CV. Andi Offset, 2007.

[30] S. E. Taylor, L. A. Peplau, D. O. Sears, “Social Psychology, $12^{\text {th }}$ Edition (in Bahasa Indonesia), ” Jakarta: Kencana Prenada Media Group, 2009.

[31] J. Wang, M. Korczykowski, H. Rao, Y. Fan, J. Pluta, R. C. Gur, B. S. McEwen, J. A. Detre, "Gender Difference in Neural Response to Psychological Stress," SCAN, vol. 2, pp. 227-239, 2007.

[32] Purwanto, "Evaluation of Learning Achievement (in Bahasa Indonesia)," Yogyakarta: Pustaka Pelajar, 2010.

[33] Y. Tang, M. Zhao, et.al., "Non-adherence to Anti-Tuberculosis Treatment among Internal Migrants with Pulmonary Tuberculosis in Shenzen, China: A Cross-sectional Study," BMC Public Health, vol. 15, no. 474, 2015.

[34] Z. Chilyatiz, Subai'ah, "Correlation between Treatment Duration and Stress Level in TB Patients of Tambelangan Public Health Center, Sampan Regency (in Bahasa Indonesia),” Jurnal Ilmiah Kesehatan, vol. 9, no. 2, pp. 183-145, 2016.

[35] A. Iqra, R. W. Yuliana, B. R. Santun, "Correlation between Treatment Duration and Stress Level in Pulmonary TB Patients in Bandung Regency, Period of March-May 2016 (in Bahasa Indonesia)," Jurnal Ilmiah Kesehatan, vol. 2, no. 2, pp. 746-751, 2016.

[36] G. S. de Araujo, S. M. Pereira, D. N. dos Santos, J. M. Marinho, L. C. Rodrigues, M. L. Barreto, M. L. "Common Mental Disorders Associated with Tuberculosis: A Matched Case-Control Study," PLoS ONE, vol. 9, no. 6, pp. e99551, 2014. 
[37] N. A. Be, W. R. Bishai, S. K. Jain, "Role of Mycobacterium Tuberculosis pknD in The Pathogenesis of Central Nervous System Tuberculosis," BMC Microbiol, vol. 12, no. 7, 2012.

[38] Y. Zadik, L. Levin, T. Shmuly, V. Sandler, and R. Tarrasch, "Recurrent Aphthous Stomatitis: Stress, Trait Anger and Anxiety of Patients," Journal of the California Dental Association, vol. 40, no. 11, pp. 879-883, 2012.

[39] G. Basu, C. Chatterjee, R. Singh, S. Biswas, "Prevalence of Depression in Tuberculosis Patients: An Experience From A DOTS Clinic," Indian Journal of Research and Reports in Medical Sciences, vol. 2, no. 4, pp. 14-17, 2012.

[40] M. A. Sulehri, I. A. Dogar, H. Sohail, Z. Mehdi, M. Azam, O. Niaz, M. S. Javed, I. A. Sajjad, Z. Iqbal, "Prevalence of Depression among Tuberculosis Patients," Annals of Punjab Medical College, vol. 4, no. 2, pp. 133-137, 2010.

[41] L-Y. Lee, H-H. Tung, S-C. Chen, C-H. Fu, "Perceived Stigma and Depression in Initially Diagnosed Pulmonary Tuberculosis Patients," Journal of Clinical Nursing, vol. 26, no. 23-24, pp. 4813-4821, 2017.

[42] F. Ambaw, R. Mayston, C. Hanlon, G. Medhin, A. Alem, "Untreated Depression and Tuberculosis Treatment Outcomes, Quality of Life and Disability, Ethiopia," Bulletin World Health Organization, vol. 96, no. 4, pp. 243-255, 2018.

[43] T. Shimamura, A. Taguchi, S. Kobayashi, S. Nagata, J. K. Magilvy, S. Marashima, "The Strategies of Japanese Public Health Nurses in Medication Support for High-Risk Tuberculosis Patients," Public Health Nursing, vol. 30, no. 4, pp. 370-378, 2013.

[44] D. P. Gilang, M. Zaenal, "Correlation between Family Social Support and Coping Mechanism in Under Treatment Pulmonary TB Patients in Legok Public Health Center (in Bahasa Indonesia),” Tangerang: Nursing Department, STIKES Widya Dharma Husada, 2016.

[45] A. Zegeye, G. Dessie, F. Wagnew, A. Gebrie, S. M. S. Islam, B. Tesfaye, D. Kiross, "Prevalence and Determinants of Anti-tuberculosis Treatment Non-adherence in Ethiopia: A Systematic Review and Meta-analysis," PLoS ONE, vol. 14, no. 1, pp. e0210422, 2019. 